Article

\title{
Design of Controlled Release System for Paracetamol Based on Modified Lignin
}

\author{
Mahboubeh Pishnamazi ${ }^{1}$, Hamid Hafizi ${ }^{1}$, Saeed Shirazian ${ }^{1}{ }^{(}$, Mario Culebras ${ }^{2}$, \\ Gavin M. Walker ${ }^{1}$ and Maurice N. Collins ${ }^{2,3, *(\mathbb{D})}$ \\ 1 Department of Chemical Sciences, Bernal Institute, Synthesis and Solid State Pharmaceutical Centre (SSPC), \\ University of Limerick, V94 T9PX Limerick, Ireland; Seyedeh.Pishnamazi@ul.ie (M.P.); \\ Hamid.Hafizi@ul.ie (H.H.); Saeed.Shirazian@ul.ie (S.S.); gavin.walker@ul.ie (G.M.W.) \\ 2 Stokes Laboratories, Bernal Institute, University of Limerick, V94 T9PX Limerick, Ireland; \\ mario.culebrasrubio@ul.ie \\ 3 Health Research Institute, University of Limerick, V94 T9PX Limerick, Ireland \\ * Correspondence: maurice.collins@ul.ie
}

Received: 15 April 2019; Accepted: 15 June 2019; Published: 18 June 2019

check for updates

\begin{abstract}
The influence of lignin modification on drug release and $\mathrm{pH}$-dependent releasing behavior of oral solid dosage forms was investigated using three different formulations. The first formulation contains microcrystalline cellulose (MCC 101) as the excipient and paracetamol as the active pharmaceutical ingredient (API). The second formulation includes Alcell lignin and MCC 101 as the excipient and paracetamol, and the third formulation consists of carboxylated Alcell lignin, MCC 101 and paracetamol. Direct compaction was carried out in order to prepare the tablets. Lignin can be readily chemically modified due to the existence of different functional groups in its structure. The focus of this investigation is on lignin carboxylation and its influence on paracetamol control release behavior at varying $\mathrm{pH}$. Results suggest that carboxylated lignin tablets had the highest drug release, which is linked to their faster disintegration and lower tablet hardness.
\end{abstract}

Keywords: lignin; drug release; paracetamol; disintegration

\section{Introduction}

Excipients play a significant role in the final product of pharmaceutical solid dosage forms. Variations in excipient properties influence tablet processability, hardness, disintegration and bioavailability [1-3]. Nowadays, many researchers have focused their investigations on using natural biopolymers [4] in tablet manufacturing due to their biocompatibility [5,6]; they are also cheap and widely available [7-9]. Lignin is a natural biopolymer with a number of beneficial properties including biodegradability and biocompatibility [10-14]. Recently, the use of lignin is increasing as a sustainable polymer for preparing carbon fibers [15], biofuels, bioplastics and controlled release carriers [16-21]. Due to the existence of different functional groups in the lignin structure such as phenolic, hydroxyl and carboxyl groups, lignin can be chemically modified to enhance drug delivery and to control drug release [22-24]. Figueiredo et al. functionalized Kraft lignin nanoparticles by carboxylation in order to improve drug delivery of poorly water-soluble anti-cancer drugs which were pH-sensitive [18]. Lievonen et al. modified softwood Kraft lignin using a dialysis technique to improve its drug delivery performance [25]. Furthermore, it has been recognized that pH-responsive drug carriers provide superior drug delivery characteristics due to their ability to increase the stability of the active pharmaceutical ingredient (API) molecules in the stomach and release the API in the intestine [26]. Li et al. investigated the release behavior of ibuprofen using lignin-based complex micelles. The results of release tests illustrated $\mathrm{pH}$-dependent and controlled release properties due to ionization of the 
carboxyl groups in the lignin structure, with repulsive forces between the negatively-charged carboxyl groups of lignin and the API molecules, with higher solubility of the API at $\mathrm{pH}=7.4$ [27]. Chen et al. synthesized lignin-based $\mathrm{pH}$-responsive nano-capsules to improve the controlled release of poorly water-soluble drugs by varying $\mathrm{pH}$ [28]. Duval et al. studied $\mathrm{pH}$ and light responsive behavior of controlled-release systems containing diazobenzen and modified softwood Kraft lignin [29]. Various investigations have been carried out on the effect of lignin-based polymeric nanoparticles (NPs) on the controlled release of pesticides [30,31].

Bulut et al. studied the controlled-release behavior of paracetamol using chitosan-graft-polyacrylamide microspheres via an emulsion crosslinking technique [32]. They utilized glutaraldehyde (GA) as a crosslinker to investigate its effect on the drug release rate. They mentioned the drug release rate was affected by some parameters such as the amount of GA, copolymer concentration and the composition of the drug and polymer. Their results illustrated that more controlled release of the drug occurred by increasing the GA amount and copolymer and decreasing the composition (paracetamol/polymer) ratio. Treenate et al. investigated the controlled release properties of paracetamol using a novel system composed of hydroxyethylacryl chitosan and sodium alginate in order to improve drug delivery for oral dosage forms [33]. Through improving drug water solubility, drug efficiency will be improved [34]. The current authors have evaluated the effect of lignin on the release rate of aspirin in oral dosage form, and indicated the higher release rate of drugs using lignin as an excipient in tablet formulation [9].

In this study, the effect of carboxylated lignin as an excipient on paracetamol release behavior was investigated. Lignin carboxylation was performed to enhance the carboxyl group content on the lignin surface in order to increase the interactions between the lignin and paracetamol functional groups and allow $\mathrm{pH}$ triggered release. To the best of our knowledge, no studies have reported the use of carboxylated lignin in paracetamol tablet manufacturing and its effect on the release. Three different formulations have been considered, one without lignin, one using pure lignin and one with carboxylated lignin. Paracetamol is utilized as a model drug in this research; it is a nonsteroidal anti-inflammatory [35]. Paracetamol is widely used as a pain relief drug as it has fast absorption within the small intestine of the human body $[36,37]$. Tablets were prepared by direct compaction and characterized using disintegration and dissolution tests. Modified lignin was verified using Fourier-transform infrared spectroscopy (FTIR). Drug release rates were measured using dissolution tests at $\mathrm{pH} 5.8$ according to the United States Pharmacopeia (USP) [38]. In order to investigate the controlled release behavior of paracetamol, dissolution tests were carried out at acidic conditions ( $\mathrm{pH}$ 1.2) and phosphate ( $\mathrm{pH}$ 7.2) buffer solutions.

\section{Experiments}

\subsection{Materials and Methods}

Paracetamol (4-acetamidophenol, Phion) was used as a model API to prepare three different formulations. Microcrystalline cellulose (MCC SANAQ®101 L USP/NF/EP) and Alcell lignin (Tecnaro, Ilsfeld, Germany) were used as excipients. More details on the lignin used in this study can be found elsewhere [2,15]. Table 1 shows the composition of the three formulations considered.

Table 1. Various formulations used in this study.

\begin{tabular}{cccc}
\hline \multirow{2}{*}{ Material } & \multicolumn{3}{c}{ Formulations } \\
\cline { 2 - 4 } & A & B & C \\
\hline Paracetamol (wt \%) & 20 & 20 & 20 \\
Alcell lignin (wt \%) & 0 & 10 & 0 \\
Modified Alcell lignin (wt \%) & 0 & 0 & 10 \\
MCC 101 (wt \%) & 80 & 70 & 70 \\
\hline
\end{tabular}

MCC $=$ microcrystalline cellulose. 


\subsection{Lignin Modification}

In order to allow conjugation reactions between lignin and paracetamol, lignin is functionalized with carboxylic acid groups. Synthesis of $\mathrm{COOH}-$ lignin involves a ring-opening reaction of succinic anhydride with 4-dimethylaminopyridine (DMAP). Lignin ( $2 \mathrm{~g})$, succinic anhydride ( $2 \mathrm{~g})$ and DMAP ( $400 \mathrm{mg}$ ) were added to $250 \mathrm{~mL}$ of tetrahydrofuran (THF) in a $500 \mathrm{~mL}$ round-bottom flask, followed by stirring for $48 \mathrm{~h}$ at room temperature [18]. The obtained carboxyl functionalized precipitate was filtered, and then, washed for $24 \mathrm{~h}$ using deionized water via the Soxhlet extraction system in order to remove the unreacted reagents. Finally, the modified lignin was placed in a freeze-dryer overnight. The proposed mechanism pathway [18] is presented in Figure 1.

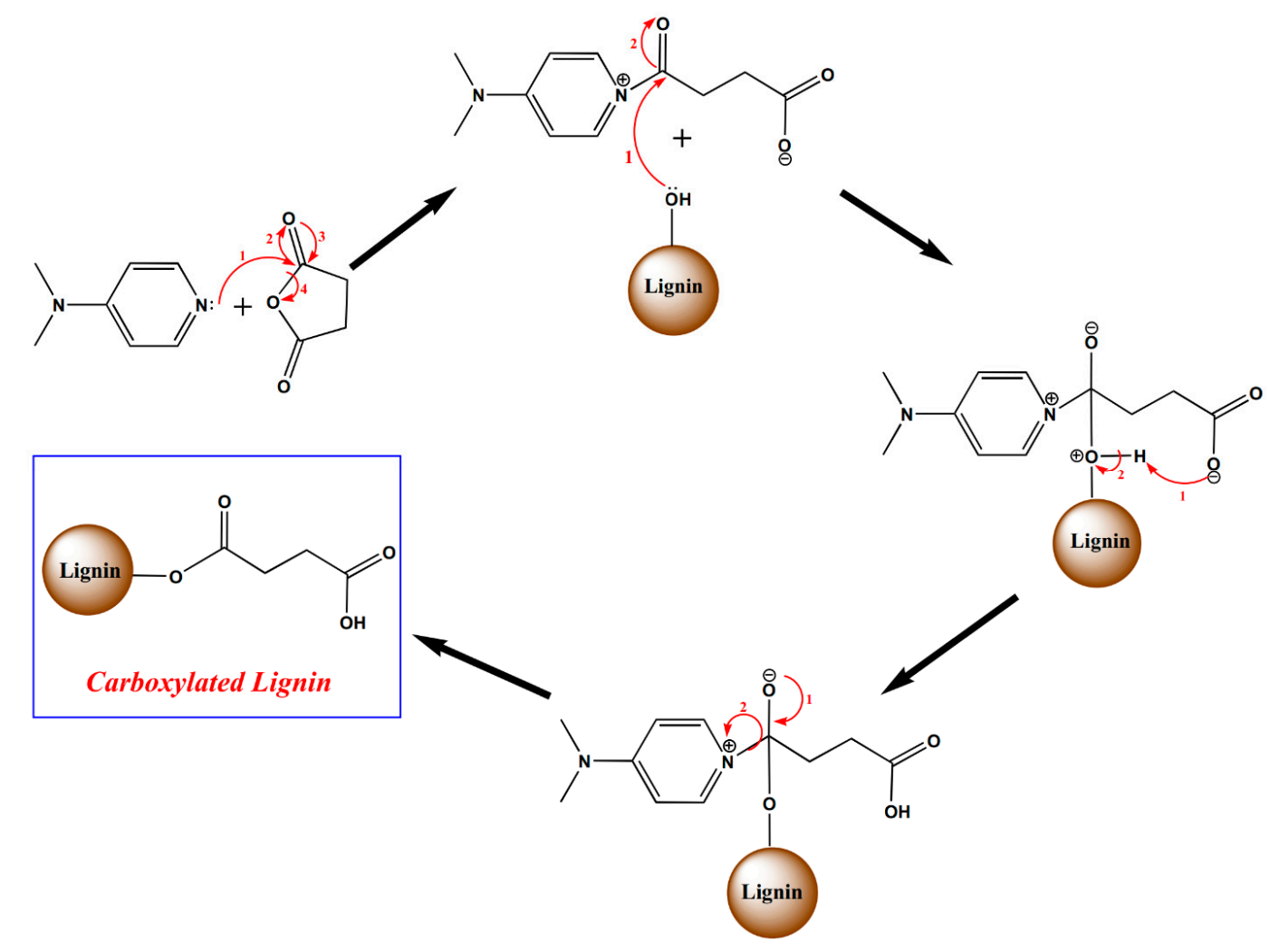

Figure 1. Mechanism of lignin carboxylation.

\subsection{Tablet Preparation}

In order to prepare the tablets, a single-punch tablet press (Gamlen Tableting GTD-1 D series) was utilized. Each formulation $(100 \mathrm{mg}$ ) was compacted to make each tablet in a $6 \mathrm{~mm}$ die. The tablet load was set at $400 \mathrm{~kg}$, with a compaction rate of $180 \mathrm{~mm} / \mathrm{min}$.

\subsection{Characterisation}

Fourier-transform infrared spectroscopy (FTIR) measurements was carried out utilizing a Nicolet Nexus FTIR spectrometer between $450-4000 \mathrm{~cm}^{-1}$ equipped with an attenuated total reflectance accessory (ATR). A total of 60 scans were performed with a spectral resolution of $2 \mathrm{~cm}^{-1}$. Tablet hardness was measured using a tablet hardness tester (Pharma Test PTB311E). Pharma Test PTZ-DIST-Disintegration Test Instrument (Hainburg, Germany) was used to measure the tablet disintegration time. Deionized water $(900 \mathrm{~mL})$ was used to fill out the apparatus vessel and the peddle speed was kept constant at $100 \mathrm{rpm}$. The temperature of the vessel was adjusted to $37^{\circ} \mathrm{C}$. The tests were performed for the two formulations containing pure lignin and carboxylated lignin until the tablets completely disintegrated. A Pharma Test PTWS 120D 6-Station Tablet Dissolution Testing Instrument 
(Hainburg, Germany) was utilized to analyze the dissolution rate of the tablets. For the measurement of drug concentration, a Cary 60 UV Spectrophotometer (Agilent Technologies, Waldbronn, Germany) was used at a wavelength of $249 \mathrm{~nm}$. All tests were carried out in triplicate. The calibration graph can be found in the Supplementary Information.

\subsection{Dissolution Test Procedure}

Phosphate buffer with $\mathrm{pH}=5.8$ (according to USP 23) was used as the dissolution medium [38,39]; $900 \mathrm{~mL}$ of medium was prepared to fill each dissolution vessel. The temperature of the medium chamber and the stirrer speed were kept constant at $37 \pm 0.5^{\circ} \mathrm{C}$ and $50 \mathrm{rpm}$, respectively. When running the dissolution test, first, the temperature should reach $37^{\circ} \mathrm{C}$. For each run, three vessels were utilized, and one tablet was considered for each vessel. Five milliliters of sample was withdrawn at $5 \mathrm{~min}, 10 \mathrm{~min}, 20 \mathrm{~min}, 30 \mathrm{~min}, 40 \mathrm{~min}, 50 \mathrm{~min}, 60 \mathrm{~min}$ and $120 \mathrm{~min}$ from each vessel and the same amount of medium was supplant, instantly. Afterwards, the samples were filtered by applying a Captiva Econofilter (PTFE membrane, $13 \mathrm{~mm}$ diameter, $0.2-\mu \mathrm{m}$ pore size). Eventually, all samples were analyzed to measure the drug concentration using a Cary 60 UV Spectrophotometer at $249 \mathrm{~nm}$ wavelength, which was calibrated to the optimal wavelength. The cuvette type was $1 / \mathrm{Q} / 10$, quartz with pathway of $1 \mathrm{~cm}$. In order to minimize the statistical error, all experiments were done in triplicate. For the dissolution tests of $\mathrm{pH}$-responsive analysis, due to the evaluation of the controlled release behavior of paracetamol in the carboxylated lignin formulation, two different $\mathrm{pHs}$ were considered: phosphate buffer solution, $\mathrm{pH}=7.2$ (intestine environment) and acidic buffer solution ( $0.1 \mathrm{~N} \mathrm{HCL}$ ), $\mathrm{pH}=1.2$ (gastric environment) $[40,41]$.

\section{Results and Discussion}

\subsection{FTIR Characterization of Pure Lignin and Modified Lignin}

The FTIR spectra analysis was carried out to monitor the pure lignin structure and to characterize the chemical changes in the functional groups of the lignin structure during the carboxylation reactions. Figure 2 shows the spectra of pure lignin and functionalized lignin, which have similar peaks, such as $\mathrm{C}=\mathrm{O}$ (carbonyl groups) at $1600 \mathrm{~cm}^{-1},-\mathrm{OH}$ (hydroxyl groups) which are attributed to the phenol and alcohol in the region of $3600-3100 \mathrm{~cm}^{-1}$ and an aromatic ring region at $1425-1514 \mathrm{~cm}^{-1}$. Nevertheless, the hydrogen-bonded hydroxyl stretching band of carboxylic acid $\left(2250-3600 \mathrm{~cm}^{-1}\right)$ and the stretching vibrations of $\mathrm{C}=\mathrm{O}$ of the unconjugated $-\mathrm{COOH}$ groups at $1720 \mathrm{~cm}^{-1}$ exhibit a stronger absorption bond than the pure lignin (unmodified), proving that grafting lignin with carboxylic acid groups has been successfully done.

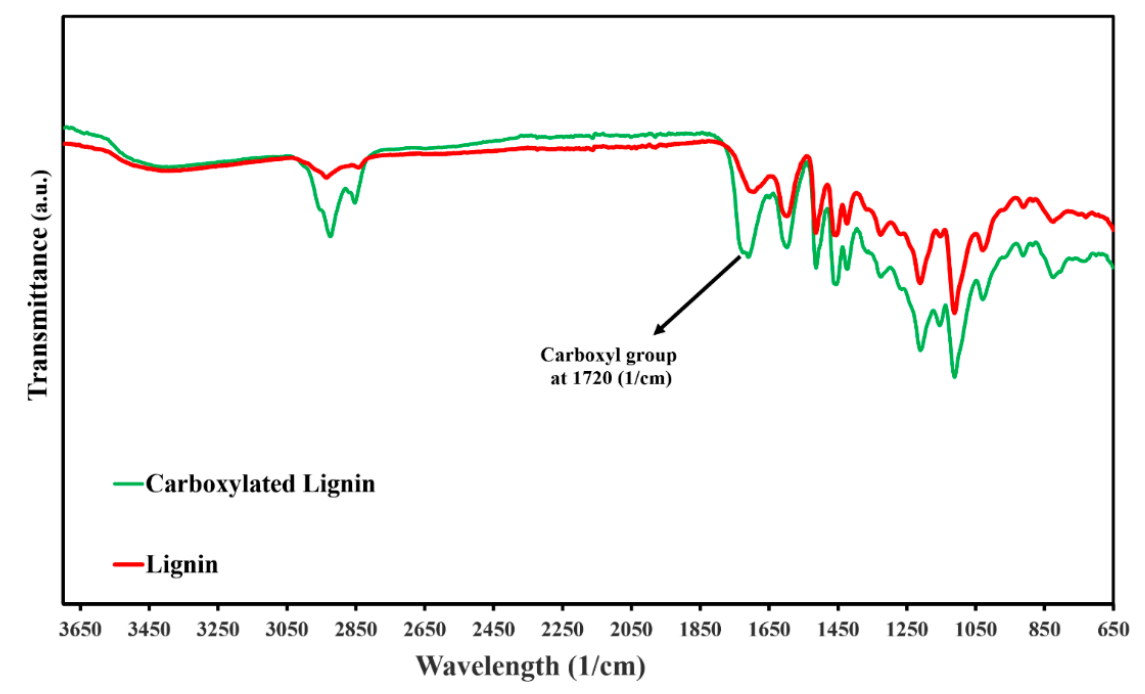

Figure 2. Fourier-transform infrared spectroscopy (FTIR) spectra of lignin (red) and carboxylated lignin (blue). 


\subsection{Effect of Lignin Carboxylation on Tablet Disintegration Time}

Tablet disintegration time affects the tablet dissolution and can be used as a valuable test for solid oral dosage forms. Tablet hardness can influence tablet disintegration time, with higher hardness leading to longer disintegration times [42,43]. In order to study the effect of lignin carboxylation on the tablet disintegration time, a disintegration test was performed for the three different tablets (non-lignin, pure lignin and modified lignin). Figure 3 presents the disintegration time results in which a faster disintegration time for tablets containing modified lignin is obtained. Moreover, tablet hardness is measured using a hardness tester (Pharma Test, PTB) for three formulations, and the results show higher hardness for the formulation without lignin (Figure 4). Tablet hardness is affected by the physical properties of materials and the interaction of the drug with the excipient. The tableting method is the same for each formulation in order to mitigate its influence on tablet hardness. Generally, lower hardness equals to higher porosity; therefore, the lower hardness and higher porosity of the carboxylated lignin tablet is due presumably to the structural differences in lignin after modification.

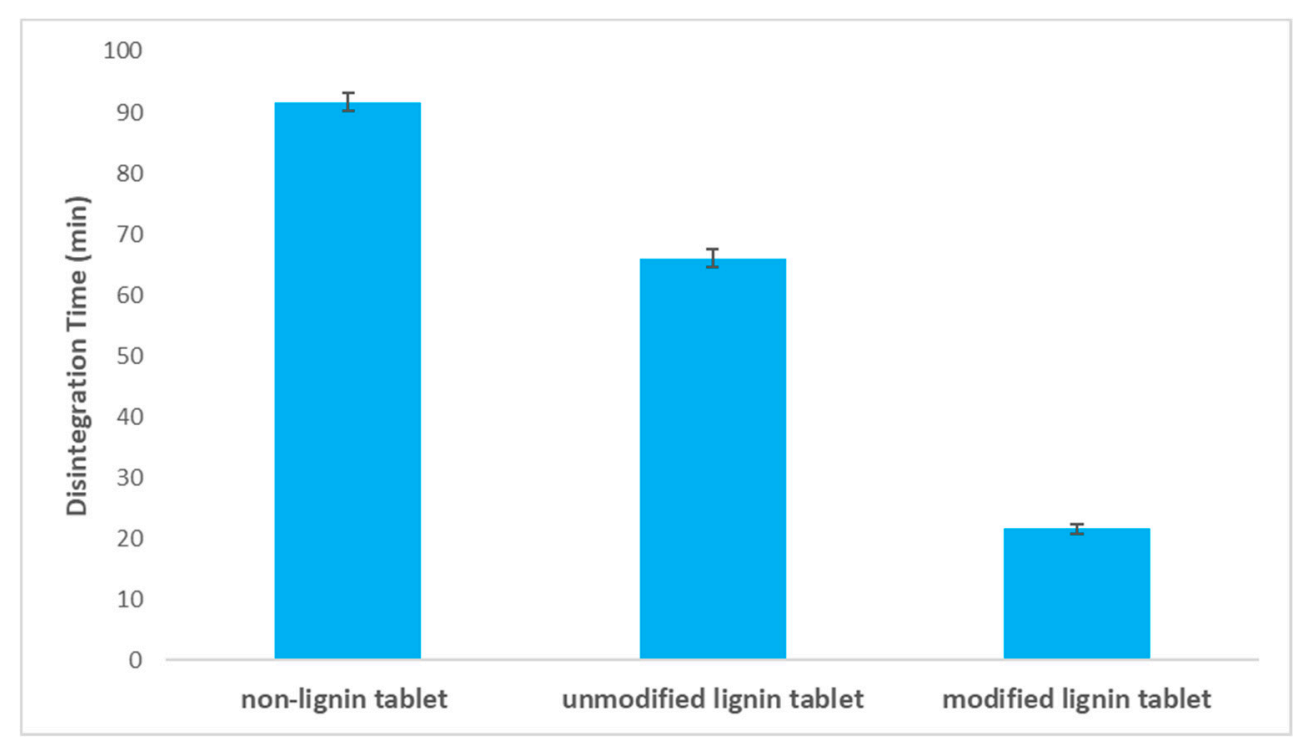

Figure 3. Disintegration time of tablets prepared containing pure lignin, modified lignin and no lignin.

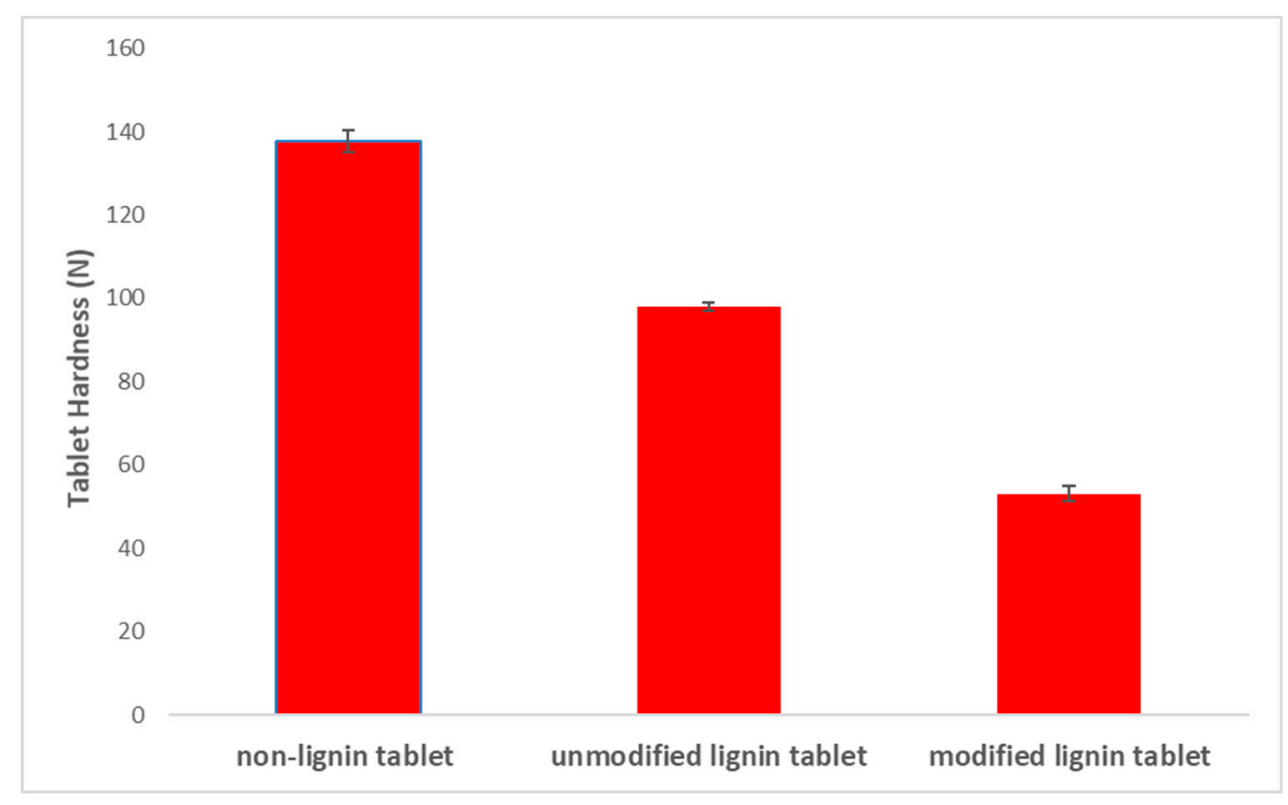

Figure 4. Hardness of tablets prepared containing pure lignin, modified lignin and no lignin. 


\subsection{Effect of Lignin Carboxylation on Drug Release Rate}

Dissolution tests were performed to evaluate the effect of lignin and carboxylated lignin on the paracetamol tablet release rate. The three different formulations in Table 1 were considered to study paracetamol release rate in phosphate buffer solution at $\mathrm{pH} 5.8$, according to the USP [38]. The release rate graphs of three different batches of paracetamol are displayed in Figure 5. Although the drug dissolution release is more dependent on the disintegration time, the formulation and material properties can influence the drug release rate. For this case, the graphs illustrate that the tablets containing functionalized lignin have the highest drug release rate and this correlates with the fastest disintegration time of these formulations and the lowest tablet hardness.

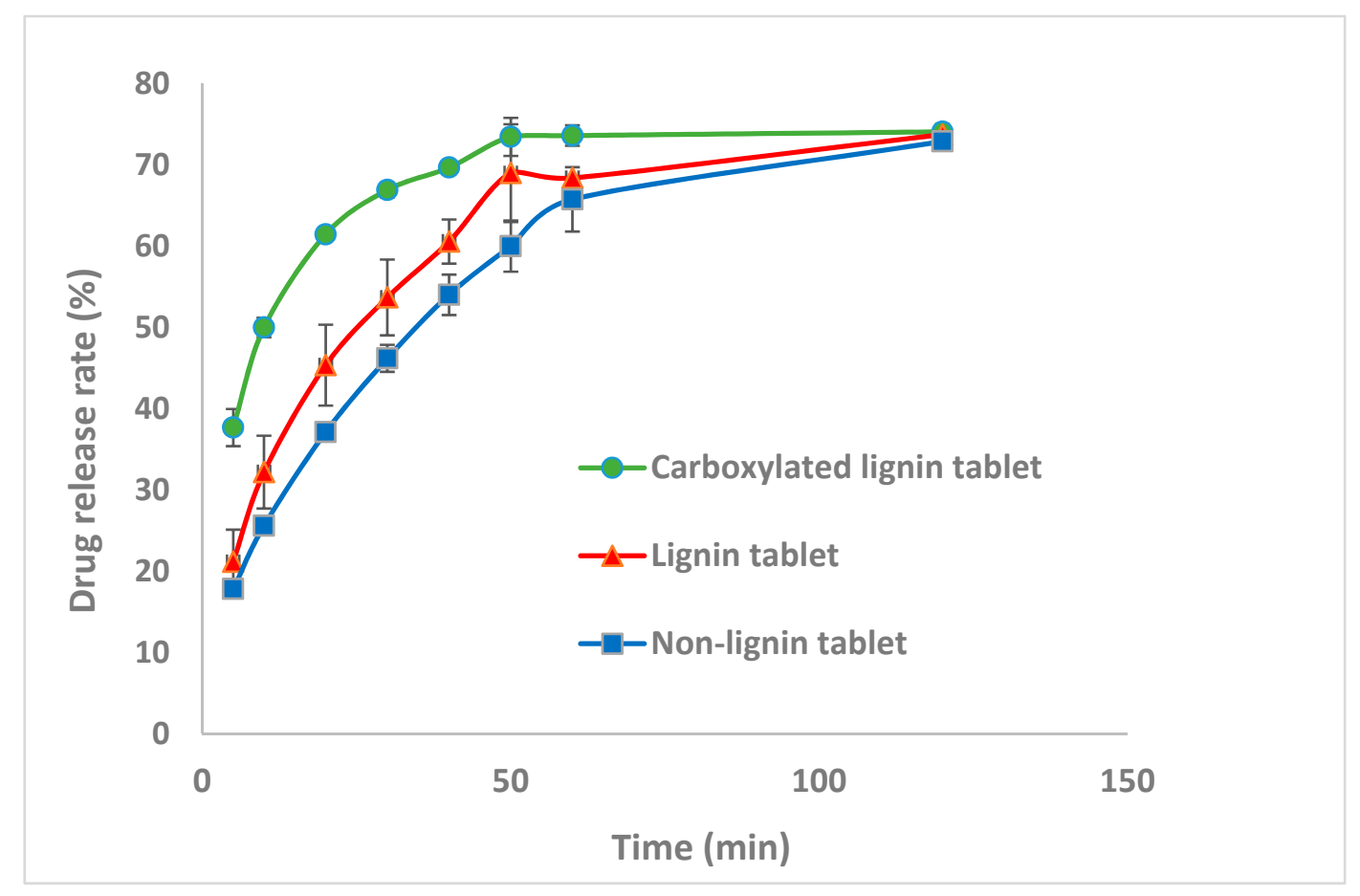

Figure 5. Drug release rate of paracetamol for the formulations at $\mathrm{pH}=5.8$.

Moreover, the prepared tablets containing pure lignin have a higher drug release rate compared to the formulation without lignin due to faster disintegration and lower tablet hardness [9]. Thus, lignin functionalization improved the release properties of directly compacted paracetamol tablets.

\subsection{Controlled Release and pH-Responsive Behavior of Carboxylated Lignin}

Drug release rate was studied in our previous work by adding lignin to the formulation [9]. The results revealed a higher drug release rate for the formulation containing lignin because of the amorphous structure of lignin and the interaction between lignin and the API, which resulted in an improvement in drug dissolution, which is the key factor in oral dosage development. Thus, for the present study, we have focused on drug controlled-release. The $\mathrm{pH}$-responsive behavior of carboxylated lignin was investigated using dissolution tests in different media at various $\mathrm{pH}$ values: $0.1 \mathrm{M} \mathrm{HCl}$ solution ( $\mathrm{pH}$ of 1.2, gastric environment) and phosphate buffer ( $\mathrm{pH} 7.2$, intestine environment) at $37^{\circ} \mathrm{C}$. The dissolution graphs in Figure 6 show a greater release rate of the drug in the buffer with $\mathrm{pH}=7.2$ [40]. Increasing the carboxyl groups results in an increase in drug release at $\mathrm{pH}=7.2$ compared to $\mathrm{pH}=1.2$. At $\mathrm{pH}=1.2$, the electrostatic repulsion between the lignin carboxyl groups decreases due to the protonation of carboxyl groups at lower $\mathrm{pH}$ values. However, at $\mathrm{pH}=7.2$, due to ionization of the carboxyl groups ( $\mathrm{pKa}=4.8$ ) of modified lignin, the negatively-charged ions repel each other and presumably this leads to a swelling effect (similar to how hydrogels swell upon 
ionization [44]) and this results in higher release rates of the API. The results of this work reveal that lignin is a promising compound for use in controlled-release systems and also for enhancing the solubility of active pharmaceutical ingredients. This is the first time that modified lignin was used for the controlled-release of paracetamol. This could be very interesting from the point of view of lignin valorization since, at the moment, the market for high value applications is very limited. The use of lignin in the pharmaceutical industry can lead to the development of new value chains for lignin promoting circular bio-economy.

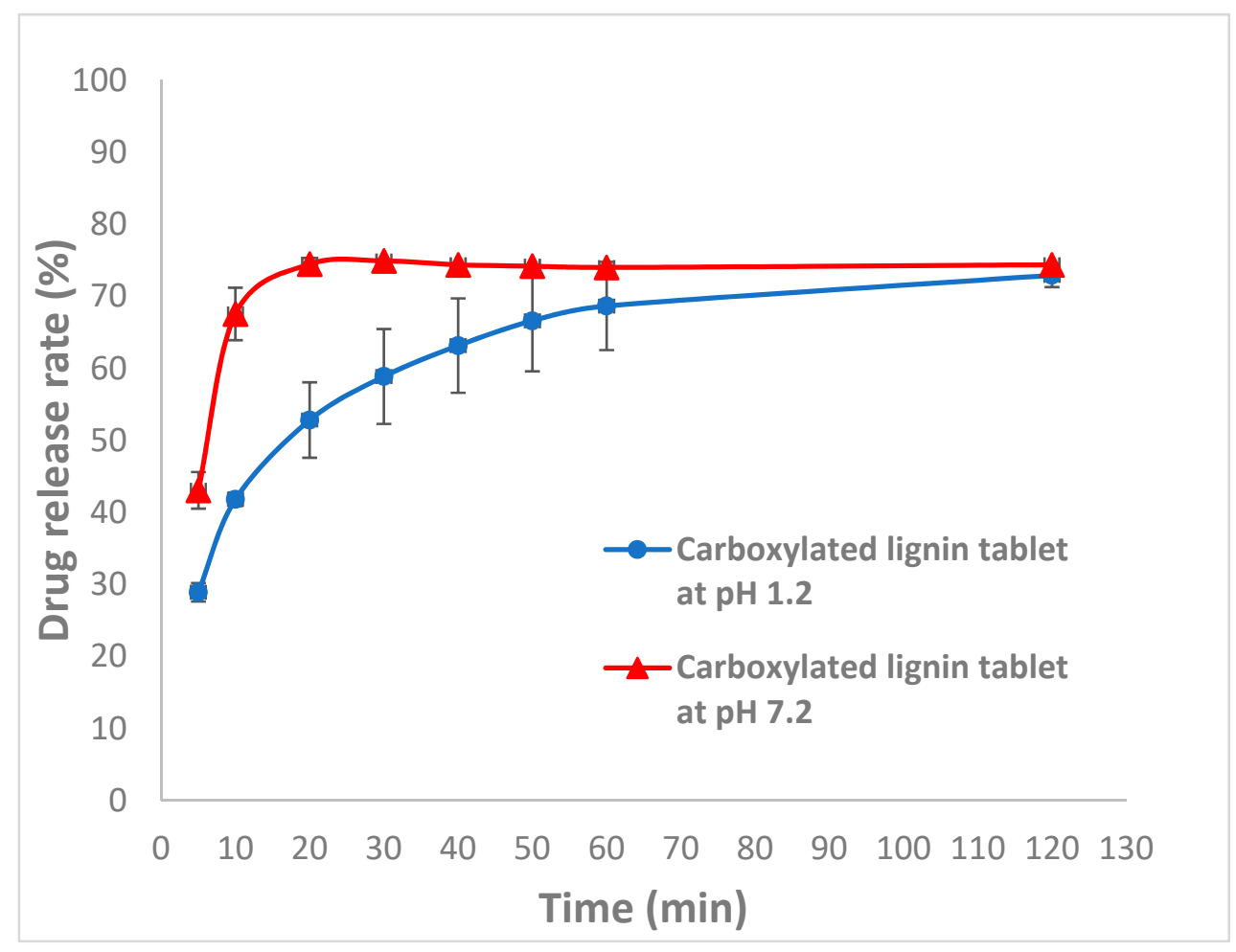

Figure 6. Drug release rate of carboxylated lignin in $\mathrm{pH}=1.2$ and $\mathrm{pH}=7.2$.

\section{Conclusions}

The aim of this study was to evaluate the $\mathrm{pH}$-dependent release behaviors of modified lignin and the effect of lignin modification on the drug release rate. Lignin modification was conducted via carboxylation of lignin functional groups. In order to analyze the carboxyl groups in the structure of lignin and carboxylated lignin, an FTIR test was carried out and the results demonstrated a successful carboxylation. The dissolution results illustrate that there is a higher release rate of paracetamol from carboxylated lignin tablets, and this is attributed to the lower degree of interaction between lignin and the API due to the deprotonation of - $\mathrm{COOH}$ groups from modified lignin. Furthermore, the controlled release behavior of carboxylated lignin was evaluated at gastric $\mathrm{pH}$ of 1.2 and intestine $\mathrm{pH}$ of 7.2, and the release results showed the successful properties of controlled release. Additionally, the tablet disintegration tests showed a faster disintegration time for the carboxylated lignin tablets compared to pure lignin tablets due to the lower hardness of tablets with modified lignin. Thus, these investigations presented a successful use of carboxylated lignin natural biopolymer as an excipient in oral dosage forms for desired drug controlled-release. 
Supplementary Materials: The following are available online at http://www.mdpi.com/2073-4360/11/6/1059/s1.

Author Contributions: Conceptualization: M.P., M.N.C., S.S. and G.M.W.; methodology: M.P., H.H., M.N.C.; software: M.P., H.H.; validation: M.P., H.H., S.S., M.C. and M.N.C.; formal analysis: M.P. and H.H.; investigation: M.P. and H.H.; resources: M.P. and H.H.; data curation: M.P.; writing-original draft preparation, M.P. and H.H.; writing—review and editing: M.P., H.H.; validation: M.P., H.H., S.S., M.C. and M.N.C.; visualization: M.P.; supervision: M.N.C. and G.M.W.; project administration: M.N.C. and G.M.W.; funding acquisition: G.M.W.

Funding: This research was conducted with the financial support of the Synthesis and Solid State Pharmaceutical Centre (SSPC), funded by SFI and is co-funded under the European Regional Development Fund under Grant Number 14/SP/2750. The authors also would like to thank Rahmatullah Shaikh, Department of Chemical Sciences, Bernal Institute, Synthesis and Solid State Pharmaceutical Centre (SSPC), University of Limerick, Limerick, Ireland, for his useful comments on UV calibration.

Conflicts of Interest: The authors declare no conflict of interest.

\section{References}

1. Zarmpi, P.; Flanagan, T.; Meehan, E.; Mann, J.; Fotaki, N. Biopharmaceutical aspects and implications of excipient variability in drug product performance. Eur. J. Pharm. Biopharm. 2017, 111, 1-15. [CrossRef] [PubMed]

2. Pishnamazi, M.; Casilagan, S.; Clancy, C.; Shirazian, S.; Iqbal, J.; Egan, D.; Edlin, C.; Croker, D.M.; Walker, G.M.; Collins, M.N. Microcrystalline cellulose, lactose and lignin blends: Process mapping of dry granulation via roll compaction. Powder Technol. 2019, 341, 38-50. [CrossRef]

3. Eraga, S.O.; Arhewoh, M.I.; Uhumwangho, M.U.; Iwuagwu, M.A. Characterisation of a novel, multifunctional, co-processed excipient and its effect on release profile of paracetamol from tablets prepared by direct compression. Asian Pac. J. Trop. Biomed. 2015, 5, 768-772. [CrossRef]

4. Chan, J.M.; Valencia, P.M.; Zhang, L.; Langer, R.; Farokhzad, O.C. Polymeric Nanoparticles for Drug Delivery. In Cancer Nanotechnology: Methods and Protocols; Grobmyer, S.R., Moudgil, B.M., Eds.; Humana Press: Totowa, NJ, USA, 2010; pp. 163-175. [CrossRef]

5. Kumari, A.; Yadav, S.K.; Yadav, S.C. Biodegradable polymeric nanoparticles based drug delivery systems. Colloids Surf. B Biointerfaces 2010, 75, 1-18. [CrossRef]

6. Frangville, C.; Rutkevicius, M.; Richter, A.P.; Velev, O.D.; Stoyanov, S.D.; Paunov, V.N. Fabrication of environmentally biodegradable lignin nanoparticles. Chemphyschem. A Eur. J. Chem. Phys. Phys. Chem. 2012, 13, 4235-4243. [CrossRef]

7. Liu, K.; Zheng, D.; Lei, H.; Liu, J.; Lei, J.; Wang, L.; Ma, X. Development of Novel Lignin-Based Targeted Polymeric Nanoparticle Platform for Efficient Delivery of Anticancer Drugs. ACS Biomater. Sci. Eng. 2018, 4, 1730-1737. [CrossRef]

8. Liu, Q.; Wang, J.; Yang, L.; Xia, X.; Wang, M.; Chen, S.; Zhu, R.; Wang, Q.; Wu, X.; Wang, S. Facile synthesis by a covalent binding reaction for $\mathrm{pH}$-responsive drug release of carboxylated chitosan coated hollow mesoporous silica nanoparticles. IET Nanobiotechnol. 2018, 12, 446-452. [CrossRef]

9. Pishnamazi, M.; Iqbal, J.; Shirazian, S.; Walker, G.M.; Collins, M.N. Effect of lignin as natural polymer on the release rate of acetylsalicylic acid tablets. Int. J. Biol. Macromol. 2018. [CrossRef]

10. Nair, L.S.; Laurencin, C.T. Biodegradable polymers as biomaterials. Prog. Polym. Sci. 2007, 32, $762-798$. [CrossRef]

11. Vinardell, M.P.; Mitjans, M. Lignins and Their Derivatives with Beneficial Effects on Human Health. Int. J. Mol. Sci. 2017, 18, 1219. [CrossRef]

12. Cheng, Y.; Zhang, H.; Xu, Z.; Wu, L.P. Advanced applications of lignin-based materials. In Functional Materials from Lignin: Methods and Advances; World Scientific Publishing: Singapore, 2018; pp. 169-205. [CrossRef]

13. Verónica, M.; Montserrat, M.; Maria, P.V. Pharmacological Applications of Lignins and Lignins Related Compounds: An Overview. Curr. Org. Chem. 2012, 16, 1863-1870.

14. Collins, M.N.; Nechifor, M.; Tanasă, F.; Zănoagă, M.; McLoughlin, A.; Stróżyk, M.A.; Culebras, M.; Teacă, C.-A. Valorization of lignin in polymer and composite systems for advanced engineering applications-A review. Int. J. Biol. Macromol. 2019, 131, 828-849. [CrossRef] [PubMed]

15. Culebras, M.; Beaucamp, A.; Wang, Y.; Clauss, M.M.; Frank, E.; Collins, M.N. Biobased Structurally Compatible Polymer Blends Based on Lignin and Thermoplastic Elastomer Polyurethane as Carbon Fiber Precursors. ACS Sustain. Chem. Eng. 2018, 6, 8816-8825. [CrossRef] 
16. Konduri, M.K.; Kong, F.; Fatehi, P. Production of carboxymethylated lignin and its application as a dispersant. Eur. Polym. J. 2015, 70, 371-383. [CrossRef]

17. Laurichesse, S.; Avérous, L. Chemical modification of lignins: Towards biobased polymers. Prog. Polym. Sci. 2014, 39, 1266-1290. [CrossRef]

18. Figueiredo, P.; Ferro, C.; Kemell, M.; Liu, Z.; Kiriazis, A.; Lintinen, K.; Florindo, H.F.; Yli-Kauhaluoma, J.; Hirvonen, J.; Kostiainen, M.A.; et al. Functionalization of carboxylated lignin nanoparticles for targeted and pH-responsive delivery of anticancer drugs. Nanomedicine 2017, 12, 2581-2596. [CrossRef] [PubMed]

19. Dalton, N.; Lynch, R.P.; Collins, M.N.; Culebras, M. Thermoelectric properties of electrospun carbon nanofibres derived from lignin. Int. J. Biol. Macromol. 2019, 121, 472-479. [CrossRef] [PubMed]

20. Witzler, M.; Alzagameem, A.; Bergs, M.; Khaldi-Hansen, B.E.; Klein, S.E.; Hielscher, D.; Kamm, B.; Kreyenschmidt, J.; Tobiasch, E.; Schulze, M. Lignin-Derived Biomaterials for Drug Release and Tissue Engineering. Molecules 2018, 23, 1885. [CrossRef] [PubMed]

21. Rais, D.; Zibek, S. Biotechnological and Biochemical Utilization of Lignin. In Advances in Biochemical Engineering/Biotechnology; Springer: Berlin, Germany, 2019; Volume 166, pp. 469-518.

22. Gilca, I.A.; Ghitescu, R.E.; Puitel, A.C.; Popa, V.I. Preparation of lignin nanoparticles by chemical modification. Iran. Polym. J. 2014, 23, 355-363. [CrossRef]

23. Figueiredo, P.; Lintinen, K.; Hirvonen, J.T.; Kostiainen, M.A.; Santos, H.A. Properties and chemical modifications of lignin: Towards lignin-based nanomaterials for biomedical applications. Prog. Mater. Sci. 2018, 93, 233-269. [CrossRef]

24. Pathania, D.; Sharma, G.; Kumar, A. Modified Biopolymers: Challenges and Opportunities; Nova Science Publishers: New York, NY, USA, 2017; pp. 1-314.

25. Lievonen, M.; Valle-Delgado, J.J.; Mattinen, M.-L.; Hult, E.-L.; Lintinen, K.; Kostiainen, M.A.; Paananen, A.; Szilvay, G.R.; Setälä, H.; Österberg, M. A simple process for lignin nanoparticle preparation. Green Chem. 2016, 18, 1416-1422. [CrossRef]

26. Liu, L.; Yao, W.; Rao, Y.; Lu, X.; Gao, J. pH-Responsive carriers for oral drug delivery: Challenges and opportunities of current platforms. Drug Deliv. 2017, 24, 569-581. [CrossRef] [PubMed]

27. Li, Y.; Qiu, X.; Qian, Y.; Xiong, W.; Yang, D. pH-responsive lignin-based complex micelles: Preparation, characterization and application in oral drug delivery. Chem. Eng. J. 2017, 327, 1176-1183. [CrossRef]

28. Chen, N.; Dempere, L.A.; Tong, Z. Synthesis of pH-Responsive Lignin-Based Nanocapsules for Controlled Release of Hydrophobic Molecules. ACS Sustain. Chem. Eng. 2016, 4, 5204-5211. [CrossRef]

29. Duval, A.; Lange, H.; Lawoko, M.; Crestini, C. Modification of Kraft Lignin to Expose Diazobenzene Groups: Toward pH- and Light-Responsive Biobased Polymers. Biomacromolecules 2015, 16, 2979-2989. [CrossRef] [PubMed]

30. Pereira, F.M.; Goncalves, A.R.; Ferraz, A.; Silva, F.T.; Oliveira, S.C. Estimation of solubility effect on the herbicide controlled-release kinetics from lignin-based formulations. Appl. Biochem. Biotechnol. 2003, 105-108, 913-919. [CrossRef]

31. Fernandez-Perez, M.; Villafranca-Sanchez, M.; Flores-Cespedes, F. Controlled-release formulations of cyromazine-lignin matrix coated with ethylcellulose. J. Environ. Sci. Health Part B Pestic. Food Contam. Agric. Wastes 2007, 42, 863-868. [CrossRef] [PubMed]

32. Bulut, E. Controlled delivery of the popular nonsteroidal anti-inflammatory drug, paracetamol, from chitosan-g-polyacrylamide microspheres prepared by the emulsion crosslinking technique. Artif. Cells Nanomed. Biotechnol. 2016, 44, 1482-1490. [CrossRef]

33. Pitchaya Treenate, P.M. Controlled release of paracetamol from $\mathrm{pH}$-sensitive hydroxyethylacryl chitosan/sodium alginate films for oral drug delivery. In Proceedings of the Burapha University Conference, Burapha University, Pattaya, Thailand, 10-12 July 2015.

34. Yoshida, T.; Lai, T.C.; Kwon, G.S.; Sako, K. pH- and ion-sensitive polymers for drug delivery. Expert Opin. Drug Deliv. 2013, 10, 1497-1513. [CrossRef]

35. Karunakaran, V.; Manickam, K.; Kandasamy, K.; Sankar, P.; Tandan, S.; Nath Sarkar, S. Arsenic decreases antinociceptive activity of paracetamol: Possible involvement of serotonergic and endocannabinoid receptors. Environ. Toxicol. Pharmacol. 2014, 38, 397-405.

36. Miyazaki, S.; Endo, K.; Kawasaki, N.; Kubo, W.; Watanabe, H.; Attwood, D. Oral Sustained Delivery of Paracetamol from In Situ Gelling Xyloglucan Formulations. Drug Dev. Ind. Pharm. 2003, 29, 113-119. [CrossRef] [PubMed] 
37. Lai, M.K.; Tsiang, R.C.C. Microencapsulation of acetaminophen into poly(L-lactide) by three different emulsion solvent-evaporation methods. J. Microencapsul. 2005, 22, 261-274. [CrossRef] [PubMed]

38. The United States Pharmacopeia, USP 23. The National Formulary, NF 18: Official from January 1, 1995; United States Pharmacopeial Convention: North Bethesda, MD, USA, 1994.

39. Ozkan, Y.; Ozalp, Y.; Savaser, A.; Ozkan, S.A. Comparative dissolution testing of paracetamol commercial tablet dosage forms. Acta Pol. Pharm. 2000, 57, 33-41. [PubMed]

40. Subramanian, K.; Narmadha, S.; Vishnupriya, U.; Vijayakumar, V. Release characteristics of Aspirin and Paracetamol drugs from tablets with Aloe Vera gel powder as a drug carrier. Drug Invent. Today 2010, 9 , 424-428.

41. Deepathomas, D.; Latha, M.S.; Kurienthomas, K. Zinc Alginate Beads for the Controlled Release of Rifampicin. Orient. J. Chem. 2018, 34, 428-433. [CrossRef]

42. Eraga, S.; Arhewoh, M.; Oc, U.; Iwuagwu, M. Investigation of the Disintegration Behaviour of Paracetamol and Metronidazole in Different Beverages. J. Sci. Pract. Pharm. 2015, 2, $23-27$.

43. Bredael, G.M.; Liang, S.; Hahn, D. A strategy for quality control dissolution method development for immediate-release solid oral dosage forms. Dissolution Technol. 2015, 22, 10-16. [CrossRef]

44. Collins, M.N.; Birkinshaw, C. Investigation of the swelling behavior of crosslinked hyaluronic acid films and hydrogels produced using homogeneous reactions. J. Appl. Polym. Sci. 2008, 109, 923-931. [CrossRef]

(C) 2019 by the authors. Licensee MDPI, Basel, Switzerland. This article is an open access article distributed under the terms and conditions of the Creative Commons Attribution (CC BY) license (http://creativecommons.org/licenses/by/4.0/). 